\title{
Dentes afiados de Vampiro
}

\author{
Vampire sharp teeth
}

Edélcio Mostaço ${ }^{1}$ 


\section{Resumo}

Resenha do livro Aristóteles ou o vampiro do teatro ocidental, da autoria de Florence Dupont. Neste ensaio a autora destaca a imperiosa presença de Aristóteles no campo da ficção e seu tratado Poética como matriz inconteste de um modelo narrativo que continua dominando o teatro e a cena do Ocidente. Ao se contrapor frente à essa hegemonia formal, histórica e ideológica, ela examina outros modelos de cenas não-dramáticas que viabilizam se falar em outros percursos possiveis para a meganarrativa do teatro entre nós.

Palavras-chave: Aristóteles; teatro ocidental; ficção; enredo

\section{Abstract}

Review of the book Aristotle or the vampire of the western theater, by Florence Dupont. In this essay the author highlights Aristotle's imperious presence in the field of fiction and his Poetic treatise as the undisputed matrix of a narrative model that dominates the theater and scene of the West. In counteracting this formal, historical, and ideological hegemony, she examines other models of non-dramatic scenes that enable to speak of other possible paths to the mega narrative of theater between us.

Keywords: Aristotle; western theater; fiction, plot

E-ISSN: 2358.6958

1 Prof. Titular. Doutor da Universidade do Estado de Santa Catarina (UDESC). Atuante na graduação e Pós-graduação em Teatro (PPGT). Bolsista PQ do CNPq. edmost@uol.com.br 


\section{Resenha da Obra:}

DUPONT, Florence. Aristóteles ou o vampiro do teatro ocidental. Florianópolis: Cultura e Barbárie, 2017, 224p.

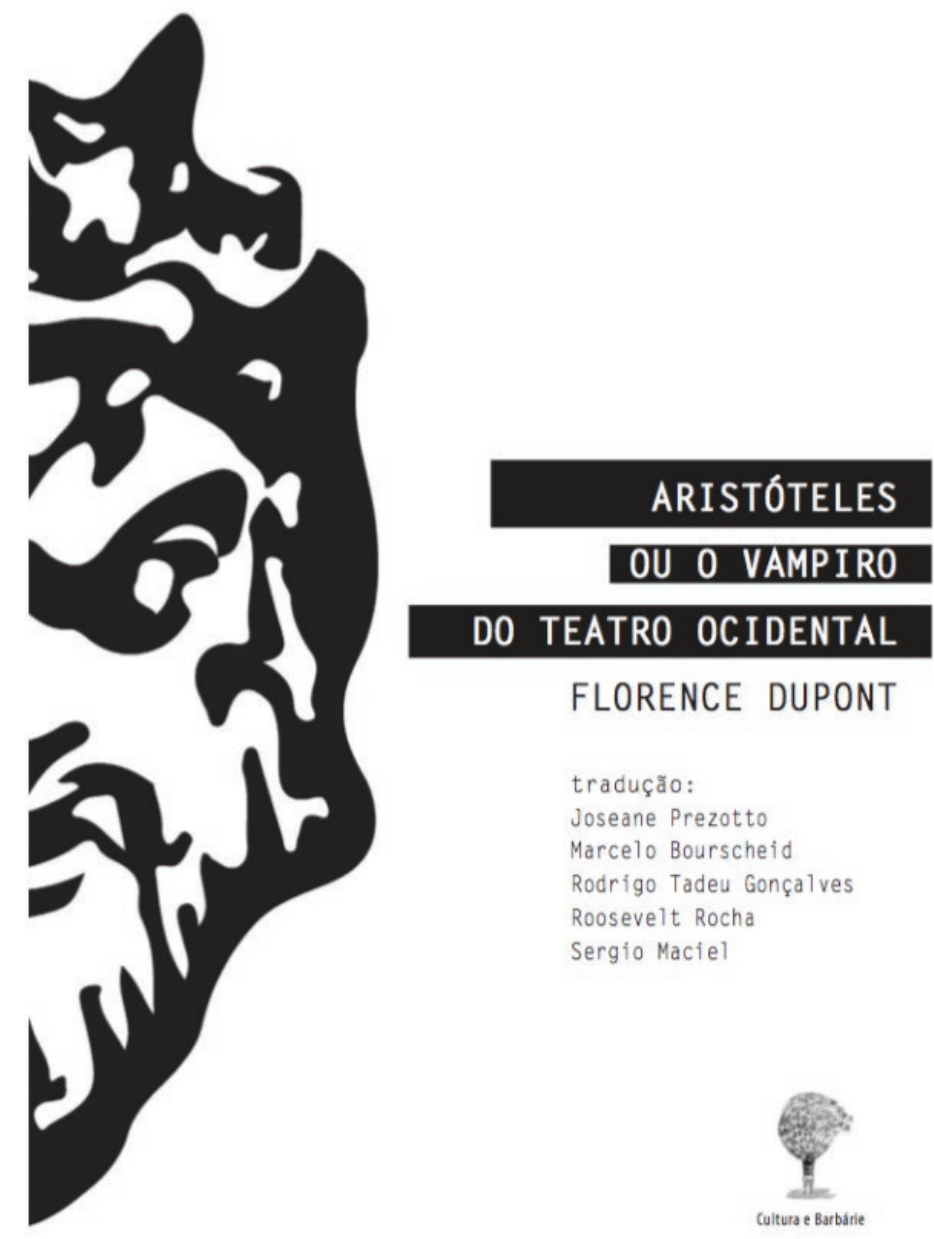

Elevado à condição de vampiro do teatro ocidental, Florence Dupont invectiva contra Aristóteles - ou melhor, contra o aristotelismo. Reconhecida e prestigiada latinista, a autora não hesita em desvendar e explicitar as principais teses que levaram a Poética, o mais consagrado tratado já produzido nos domínios das artes cênicas, à condição não apenas de cânone universalista destinado a regrar todas as narrativas, como, sobretudo, a funcionar como antibiótico em relação à criatividade do fictício.

A obra em questão - Aristóteles ou o vampiro do teatro ocidental - surgiu em 2007 e se passaram dez anos até ser traduzida em português, pela editora catarinense Cultura e Barbárie. Primeira obra da autora em vernáculo, pode-se dizer que Dupont permanece virtualmente desconhecida entre nós, embora seja diretora de pesquisa no Collège International de philosophie em Paris e reúna, entre outros títulos de sua lavra, O erotismo masculino na Roma antiga (2001), A insignificância trágica (2001), 
O orador sem rosto, ensaio sobre o ator romano e sua máscara (2000). Mas ela é sempre citada e lembrada em função de seu primeiro texto: Homero e Dallas - introdução à uma crítica antropológica, lançado em 1991, no qual cometeu o desplante de comparar os poemas homéricos com uma infindável e famigerada série de televisão muito popular na ocasião, o que provocou escândalo entre as hostes mais conservadoras dos estudos literários.

Todos sabem que o mythos - traduzido possivelmente como enredo, fábula e até mesmo intriga nas versões correntes da Poética - ocupou a maior atenção de Aristóteles, principal parte da tragédia e verdadeira máquina de guerra que tudo submete a seus desígnios. Segundo Dupont, "o mythos não preexiste à tragédia - não é um velho mito ancestral -, mas resulta do trabalho do poeta que reúne e organiza ações, ou seja, feitos realizados pelos homens - pragmata ou práxis - que podem ser dados pela tradição ou inventados pelo poeta. [...] Note-se também que o mythos não é em si mesmo uma ação, ele é a sua representação (mimesis)" (p. 30). A partir dessa observação inicial, a autora vai atestando, argumento após argumento, como a tragédia aristotélica foi pensada enquanto um dispositivo centralizador em relação à narrativa e à cena, recalcando seus sentidos sobre a representação da ação (as tais pragmata e práxis) que insistem em se impor sobre qualquer outra dimensão presente na primitiva cerimônia da qual a tragédia se originou.

Restaram perdidas, portanto, inúmeras outras dimensões do antigo komos, cujas mais significativas, de uma perspectiva atual, seriam as práticas rituais, seu caráter musical e dançado, seus sentidos gregário e coletivo e, acima de tudo, sua condição performativa. Os intérpretes da tragédia, qualificados por Aristóteles como prattontes (agentes), foram despossuídos de qualquer singularidade enunciativa, de qualquer modalização ou subjetivação, apenas meros vocalizadores de um texto prévio da autoria de um poeta, e promovido, em acordo com o sistema filosófico preconizado pelo Estagirita, como a causa final de todo o conjunto. Ademais, a prevalência da tragédia sobre a comédia é outro fator que desmoraliza um gênero frente ao outro, apequenando o presente e o vivo inerentes ao humor em relação à reverência e memória oriundas do passado.

Como sabido, foi nula a participação da Poética no teatro romano. Fruto de uma confluência de manifestações diversas que espocaram na Península Itálica nas várias regiões cobertas pela latinidade, as atelanas, os mimos, os ludi scaenici etruscos e a forma dupla da palliata (praetexta e togata) não foram alteradas após o contato com a Grécia. E as imitações gregas romanizadas de Ênio e Pacúvio pouco são lembradas, dada sua virtual nulidade naquele ambiente efusivo que privilegiou, sobretudo, os ludi romani como um denominador comum à todas as manifestações que faziam da cena seu motivo central. Terêncio, e sobretudo Plauto, legaram um conjunto de comédias esfuziantes, que ainda hoje podem subir à cena com desenvoltura, marco maior de uma tendência que possui no grego Aristófanes seu mais agudo vértice. De modo que o teatro que subsistiu dos períodos arcaicos foi o cômico, com ênfase sobre a jocosidade, a diversão, a espetacularização, e mesmo a licença e a obscenidade, em detrimento dos temas sérios e cívicos. A Epístola aos Pisões (ou Arte Poética, de Horácio), as Instituições Oratórias (de Quintiliano) e as anotações de Donato servi- 
ram, ao longo de toda a Idade Média, como as referências conceituais mais significativas quanto à arte cênica proveniente da Antiguidade. Preservada através de cópias relegadas aos mosteiros, a Poética permaneceu desconhecida até o século XV.

De modo que, nos raciocínios de Florence Dupont, a prevalência da festa, da inventividade, do prazer de viver e do espírito de congraçamento que as atividades cênicas já desfrutaram no Ocidente não se coadunam com o aristotelismo, como ele veio, posteriormente, a se estruturar. Uma invenção moderna, segundo ela, uma meganarrativa construída a partir de três momentos áureos inscritos na tradição europeia.

O primeiro deles é o lluminismo, com a ativa participação de Goldoni no que é conhecido como "reforma da commedia dell'arte", momento de subjugação do ator frente ao autor, na esteira daquilo que Aristóteles já iniciara em seu tratado. Outro passo nessa direção foi dado por Diderot, não apenas quanto a seu preconizado esvaziamento emotivo relativo aos interpretes, como, sobretudo, suas noções conceituais de quadro e de quarta parede; desenhando o primeiro croqui do que em breve virá a ser o drama burguês. E com Rousseau nos deparamos com um paradoxo: ele recusou o teatro, mas tentou preservar o ritual em sua Carta a d'Alambert, situação que não retira de seu calvinista juízo a censura contra tudo o que considerou conspurcação cênica.

O segundo pico do aristotelismo está emaranhado nas últimas décadas do século XIX, em torno do triunfo da encenação. Antoine e Stanislávski podem ser considerados os próceres desse revival, às custas da organização da narratividade cênica por eles desencadeada. Se agora já não é mais o autor a dar as cartas quanto à geração e à organização da ficção, esta foi deslocada para as mãos e os olhos do encenador e, em breve tempo, teremos o implemento do que costumeiramente se denomina textocentrismo, o triunfo de uma ideia central (que pode estar no texto ou na ideologia do encenador) como uma norma para a realização cênica. Mesmo quando esta é oferecida às considerações da recepção: "na verdade, a história da encenação no século $X X$ apresenta-se como uma sequência de ataques recorrentes, conduzidos por encenadores inovadores, contra a teatralidade de sua época, em nome de uma verdade da representação", pondera a autora (p. 88).

$E$, culminando a série, um terceiro momento logocêntrico surge exatamente com aquele que se propôs criar uma dramática anti-aristotélica: Bertolt Brecht. Embora pugnando por um teatro inovador e distanciado, é notória a preferência do autor de Mãe Coragem pela fábula. Isso porque, para um teatro político, é novamente a práxis da personagem o que mais importa, uma vez que motiva a discussão de suas ideias e a ética de seus atos praticados, possibilitando à plateia a almejada tomada de consciência. "Portanto, para Brecht, a mimesis é essencial. No início de seu ensaio [Pequeno Órganon para o Teatro], ele define a mimesis e a função teatral em termos diretamente emprestados à Poética: 'o teatro consiste em produzir reproduções vivas (lebende Abbildungen) de acontecimentos narrados ou inventados entre pessoas, tendo a diversão como finalidade'", adverte Dupont ao citar o drmaturgo (p. 109).

Torna-se curioso perguntar o que pode ser a diversão no contexto brechtiano, uma vez que ela substitui a kátharsis aristotélica, mas nunca é explicada pelo autor de Augsburg. O máximo que ali se diz é que "há um prazer em aprender", coisa que, 
de resto, também já figura na Ética a Nicômaco do autor grego - situação que reaproxima ambos frente a um simétrico projeto artístico: estruturar a fábula ou mythos.

Desnecessário enfatizar como todo o chamado teatro político de inspiração brechtiana se tornou caudatário de suas teses principais e, notadamente, seu retorno à estrutura da fábula enquanto fator decisivo de inflexão. Para Dupont, "Brecht tem em comum com Aristóteles uma recusa total e definitiva dos teatros rituais, que ele acusa de paralisar o público. [...] O distanciamento brechtiano não é a metateatralidade. O distanciamento apenas se utiliza dela. A metateatralidade não é lúdica, mas pedagógica" (p. 112).

Ao destacar esses três momentos em que o aristotelismo cênico e narrativo se agigantou e contribuiu para a formação da meganarrativa que estabelece o triunfo do drama como forma paradigmática do teatro praticado no Ocidente, Florence Dupont tem seu olhar voltado para outras matrizes cênicas. Embora ela não explicite, é possível surpreender em seu discurso certo tom decolonial e, acrescento eu, de enfrentamento quanto à construção logocêntrica que toda a metafísica erigiu como modelo de pensamento.

Isso fica mais claro na terceira parte de seu livro, onde ela enfoca os teatros-não-dramáticos de todas as épocas, geralmente escamoteados ou ausentes nas toscas e mal-ajambradas histórias do teatro correntes, apenas um perfilar de nomes de autores e textos dramáticos exemplares na perspectiva do textocentrismo. O caso mais escabroso está associado à tragédia ateniense, não apenas em função do aristotelismo como, ademais, das ingerências filosóficas e filológicas da qual ela foi e ainda é vítima. Sobre essa questão específica, sugiro a consulta a um percuciente estudo de Erika Fischer-Lichte que deslindou em pormenores o longo e enviesado percurso valorativo tomado pela tragédia na Alemanha, com especial destaque para as considerações efetuadas por Hegel, Schiller e Schlegel, e a seguir Nietzsche². A partir dali, a tragédia perdeu suas características rituais, deixou de ser música e dança, para tornar-se sobretudo uma poesia textual que destila gota a gota agudos enigmas filosóficos. Na França do final do século XX alguns estudiosos já deslindaram tais equívocos, mas ainda há muito a se fazer para restituir à tragédia ateniense remanescente tudo o que possui de refratário ao sangue vampiresco que escorre dos dentes aristotélicos da Poética.

A comédia romana de Plauto é outro ponto de inflexão analisado por Dupont, ao ressaltar na verificação de sua estrutura as partes ou interlúdios isolados que esfacelam qualquer intenção de contar um enredo ou apresentar uma ação encenada, mas tão somente fazer parte de um evento maior que objetivava o jogo e a diversão. "O teatro de jogo, ao contrário do teatro dramático, é uma performance cujo objetivo não é representar uma história, mas celebrar esse ritual que os romanos chamavam de 'jogos' (ludi)" (p. 130).

Um novo e eloquente exemplo de um teatro não-dramático está em Moliére, sobretudo em suas óperas-balés, que emprega recursos metateatrais que não devem ser confundidos simplesmente com o teatro dentro do teatro, como afirma certa tradição subserviente às bienseances. Uma longa análise de O Burguês Fidalgo dá conta

2 Ver Tragedy's Endurance - performances of Greek Tragedies and Cultural identity in Germany since 1800; sendo útil, igualmente, a consulta a um outro título seu: Theatre, Sacrifice, Ritual. 
dessas incongruências, revelando que sua pretensa fábula foi, em realidade, sugerida pelo próprio Luis XIV, após uma visita de embaixadores turcos e que ele queria uma turqueria para alegrar as noitadas da corte. O Senhor Jourdain, assim, se transforma no Grande Mamamouchi não por um truque de teatro, mas porque não havia melhor solução para recriar em Versalhes a fantasia arábica idealizada pelo soberano. Molière e Lully, autores da obra, trabalharam juntos todas as coreografias e a estrutura musical que sustentavam a realização, toda ela picotada por ações descontínuas.

Se o teatro pós-dramático e performativo não constitui exatamente oposições a um teatro não-dramático, uma vez que reportam o espelhamento invertido da monocrática presença da fábula aristotélica em seus horizontes, um outro modo de considerar a cena é rever toda a história do teatro no Ocidente a partir de um ponto de vista que recuse o aristotelismo. Esse é o generoso e desafiador convite que Florence Dupont aqui efetua, a partir de um roteiro cuidadosamente elaborado e conceitualmente sustentado. Portanto, aux armes, citoyens!

\section{Referências}

DUPONT, Florence. Aristóteles ou o vampiro do teatro ocidental. Florianópolis: Cultura e Barbárie, 2017.

FISCHER-LICHTE, Erika. Tragedy's Endurance, performances of Greek Tragedies and Cultural identity in Germany since 1800. Oxford University Press, 2017.

FISCHER-LICHTE, Erika. Theatre, Sacrifice, Ritual - exploring formes of political theatre. London and New York: Routledge, 2005.

Recebido em: 05/09/2019

Aprovado em: 16/10/2019 